\title{
Effects of pre-operative air-powder polishing and rubber-cup prophylaxis on tooth bleaching: Randomized controlled split-mouth clinical study
}

zeliha gonca bek kurklu ( $\sim$ goncabek@mynet.com )

Cukurova Universitesi Dis Hekimligi Fakultesi https://orcid.org/0000-0002-4726-7883

mustafa ozcan

Cukurova Universitesi Dis Hekimligi Fakultesi

\section{Research article}

Keywords: CIELab, CIEDE2000, prophylaxis, shade guide, spectrophotometer, tooth bleaching

Posted Date: October 29th, 2020

DOI: https://doi.org/10.21203/rs.3.rs-61068/v2

License: (c) (i) This work is licensed under a Creative Commons Attribution 4.0 International License.

Read Full License 
1 Type of article: Original Research Article

2 Title of the article: Effects of pre-operative air-powder polishing and rubber-cup

3 prophylaxis on tooth bleaching: Randomized controlled split-mouth clinical study

$4 \quad$ Running title: Effect of prophylaxis technique on tooth bleaching

6 Contributors

7 1. Zeliha G Bek Kurklu, DDS, PhD, Assistant Professor, Department of Restorative 8 Dentistry, Faculty of Dentistry, Cukurova University, Turkey

92 . Mustafa Ozcan, DDS, PhD, Assistant Professor, Department of Periodontology,

10 Faculty of Dentistry, Cukurova University, Turkey

12 Corresponding Author:

13 Name:Zeliha Gonca Bek Kurklu

14 Address: Cukurova University, Department of Restorative Dentistry, Saricam, Adana,

15 Turkey

16 Phone numbers: +90 5334500892

17 E-mail address: goncabek@mynet.com

19 Name: Mustafa Ozcan

20 Address: Cukurova University, Department of Periodontology, Sarıcam, Adana, Turkey

21 Phone numbers: +90 5552288211

22 E-mail address: mustafaozcan@cu.edu.tr 

trial*

opic

o Checklist item

No

\section{Title and abstract}

1a Identification as a randomised trial in the title

Title

page,

paragra

ph 2

1b Structured summary of trial design, methods, results, and Page 2, conclusions (for specific guidance see CONSORT for abstracts) paragra

ph

$1,2,3,4$

\section{Introduction}

Backgrou 2a Scientific background and explanation of rationale

Backgr

nd and

ound,

objectives

paragra

ph 4

2b Specific objectives or hypotheses

Backgr

ound, 


\section{Methods}

Trial 3a Description of trial design (such as parallel, factorial) including Method

design allocation ratio $\mathrm{s}$
paragra
ph 1

3b Important changes to methods after trial commencement (such Method as eligibility criteria), with reasons

$\mathrm{S}$,

paragra

ph 1

Participan 4a Eligibility criteria for participants

Method

ts

S,

paragra

ph 3,4

$4 \mathrm{~b}$ Settings and locations where the data were collected

Method

$\mathrm{S}$,

paragra

ph 2

Interventi 5 The interventions for each group with sufficient details to allow Method

ons replication, including how and when they were actually $\mathrm{s}$, administered paragra

ph 7

Outcomes 6a Completely defined pre-specified primary and secondary Method outcome measures, including how and when they were assessed $\mathrm{s}$, 
paragra

ph 10

$6 \mathrm{~b}$ Any changes to trial outcomes after the trial commenced, with No reasons change

Sample $\quad 7 \mathrm{a} \quad$ How sample size was determined Method

size

$\mathrm{s}$,

paragra

ph 5

7b When applicable, explanation of any interim analyses and Method stopping guidelines

S,

pragrap

h 6

Randomis

Method

ation:

S,

paragra

ph 6

8a Method used to generate the random allocation sequence

Seq $8 b$ Type of randomisation; details of any restriction (such as Method uenc blocking and block size

$\mathrm{s}$,

e

paragra

gene ph 6

ratio

$\mathrm{n}$ 
9 Mechanism used to implement the random allocation sequence $\overline{\text { Method }}$ Allo (such as sequentially numbered containers), describing any steps s,paragr cati taken to conceal the sequence until interventions were assigned aph 6 on conc eal men $\mathrm{t}$ mec hani sm

10 Who generated the random allocation sequence, who enrolled Method Implemen participants, and who assigned participants to interventions $\mathrm{s}$, tation paragra ph 6

Blinding 11 If done, who was blinded after assignment to interventions (for Method a example, participants, care providers, those assessing outcomes) s, and how pragrap h 6,7

11 If relevant, description of the similarity of interventions Method b $\mathrm{s}$, paragra ph 7,8

Statistical 12 Statistical methods used to compare groups for primary and Method methods a secondary outcomes s, 
12 Methods for additional analyses, such as subgroup analyses and Non

b adjusted analyses

\section{Results}

Participan 13 For each group, the numbers of participants who were randomly Figure 1

$\mathrm{t}$ flow (a a assigned, received intended treatment, and were analysed for the diagram is primary outcome

strongly 13 For each group, losses and exclusions after randomisation, Figure 1 recomme $\quad b \quad$ together with reasons

nded)

Recruitme 14 Dates defining the periods of recruitment and follow-up Result, $\mathrm{nt}$

Baseline 15 A table showing baseline demographic and clinical Result, data characteristics for each group paragra ph 1, table 1

Numbers 16 For each group, number of participants (denominator) included Result, analysed in each analysis and whether the analysis was by original paragra assigned groups ph 1 
Outcomes 17 For each primary and secondary outcome, results for each group, Table

and a and the estimated effect size and its precision (such as 95\% 2,3,4,5

estimation confidence interval)

17 For binary outcomes, presentation of both absolute and relative Non

b effect sizes is recommended

Ancillary 18 Results of any other analyses performed, including subgroup Non

analyses analyses and adjusted analyses, distinguishing pre-specified from exploratory

Harms 19 All important harms or unintended effects in each group (for Non specific guidance see CONSORT for harms)

\section{Discussion}

Limitatio 20 Trial limitations, addressing sources of potential bias, Discuss

ns imprecision, and, if relevant, multiplicity of analyses ion,

paragra

ph 9

Generalis 21 Generalisability (external validity, applicability) of the trial Conclus $\begin{array}{lll}\text { ability findings } & \text { ion }\end{array}$

Interpretat 22 Interpretation consistent with results, balancing benefits and Discuss ion harms, and considering other relevant evidence ion,

paragra

ph 2,3

Other information

Registrati 23 Registration number and name of trial registry

Abstrac

on

$\mathrm{t}$ 
Protocol 24 Where the full trial protocol can be accessed, if available

Ethics
approva
$1 \quad$ and
consent
to
particip
ate

Funding $\quad 25$ Sources of funding and other support (such as supply of drugs), Fundin role of funders g

$30 *$ We strongly recommend reading this statement in conjunction with the CONSORT 2010

31 Explanation and Elaboration for important clarifications on all the items. If relevant, we also

32 recommend reading CONSORT extensions for cluster randomised trials, non-inferiority and

33 equivalence trials, non-pharmacological treatments, herbal interventions, and pragmatic trials.

34 Additional extensions are forthcoming: for those and for up to date references relevant to this

35 checklist, see www.consort-statement.org. 
ABSTRACT

Background: The aim the study to compare the effects of pre-operative air-powder polishing and rubber-cup prophylaxis on tooth bleaching.

Methods: 23 subjects suffering from discoloration, were enrolled in a randomized controlled split mouth experimental study. Before bleaching, air powder polishing (APP) and rubber-cup polishing (RCP) techniques were applied on either side of the mouth. A $40 \%$ hydrogen peroxide bleaching agent applied two 15-minute applications for in-office bleaching. The tooth bleaching effects assessed immediately after and 1 week.

Results: There were no significant differences between prophylaxis groups with respect to all color parameters $(\Delta \mathrm{L}, \Delta \mathrm{a}, \Delta \mathrm{b}, \Delta \mathrm{SGU}, \Delta \mathrm{Eab}, \Delta \mathrm{E} 00)$ at immediate period $(\mathrm{p}>0,05)$. At 1 week assessment period there were no significant differences between prophylaxis groups with respect to all color parameters $(\mathrm{p}>0,05)$ except delta E00 $(\mathrm{p}<0,05)$.

Conclusions: Two prophylaxis techniques produced similar efficacy in bleaching treatment and the APP technique produced higher levels of color changes.

Trial registration: ClinicalTrial.gov ID: NCT04407910

Keywords: CIELab, CIEDE2000, prophylaxis, shade guide, spectrophotometer, tooth bleaching 


\section{Background}

Vital bleaching treatment in dentistry are classified as in-office bleaching and at-home

bleaching. Currently, in- office bleaching gels are the most commonly used agents and contain high hydrogen peroxide concentrations (typically 15-40\%) while at-home bleaching products usually contain $3-10 \%$ of hydrogen peroxide [1]. The in-office bleaching technique has some advantages such as avoiding soft tissue irritation, preventing the use of excess material and producing immediate esthetic results $[2,3]$.

The agents used in bleaching treatment could penetrate enamel/dentin and oxidize the molecules of the substances that cause discoloration in the tissue. In the bleaching reaction, peroxides convert into peroxide radicals, which have singular and unpaired electrons with no electronic charge. These highly reactive radicals have a high affinity for double bonds. Peroxide radicals bond to and destroy the carbon-carbon double bonds of the chromophore and either convert them into single bonds or completely break down [4]. The resulting molecules are colorless and make teeth look whiter.

Various factors are reported to effect tooth bleaching such as bleaching type, concentration, time and other factors (ie. plaque, pellicle on the tooth surface) [5]. The success of bleaching is directly related to the diffusion capacity of peroxides to enamel and dentin. The penetration of hydrogen peroxide in the tooth structure is time-dependent [6].

Up to date various studies have been performed to increase the effectiveness of the bleaching procedure in a shorter period of treatment time. In-office bleaching usually requires long application period and sometimes additional visits to obtain optimum results. Prolonging bleaching treatment may result in several side-effects such as tooth sensitivity, gingival irritation and alteration of enamel surface [7,8]. Low molecular weight of HP diffuses through permeable enamel and dentin substrates, then reaches the pulp chamber via the dentinal tubules. 
Exposure to high HP concentrations, may cause inflammatory response in the pulp. Less application and sessions are recommended to minimize these side effects [9-11]. Researchers investigated whether reduced contact time of the bleaching gels could yield less-adverse effects while still being effective $[10,12,13]$. Several studies have shown that the substance released from bleaching gels is proportional to their contact time with enamel [14-17]. However, some authors have shown that exposure of pulp cells to low HP concentrations encourages the differentiation of odontoblasts and the formation of mineralization $[18,19]$. On the other hand, shortening the bleaching time may prevent it from achieving satisfactory results. The gel used in the in-office technique is exposed to the environment and seemingly loses water faster. This is the argument used by manufacturers to recommend applications of 15 minutes. The shortest time of application (2X15 minutes) for one session as recommended by the manufacturer was performed in the current study.

The activation of bleaching agents is limited and decreases over time [20]. Contact with plaque and external stains before tooth enamel during active time of agent might reduce its effectiveness. The superficial stains, plaque accumulation, and microorganisms formed on the outer surface of tooth enamel should be removed before starting bleaching treatment by polishing in order to make bleaching agent more effective. Dental bleaching manufacturers recommend dental prophylaxis before bleaching treatment in their instruction manuals. But there is no research about prophylaxis techniques before bleaching treatment.

The most common method of polishing is rotary rubber-cup prophylaxis with various types of pastes. These polishing pastes include flour of pumice, glycerine and fluoride. Air-powder polishing devices (APDs) are an alternative to rubber cup polishing. These devices use a slurry of water, abrasive powder and pressurized air to clean or polish tooth surface [21]. Sodium bicarbonate is the first air-polishing powder used with these devices. There are many literature 
stating that air polishers are more effective and efficient in removing extrinsic stain and plaque

120 from tooth surfaces than rubber cup polishers [22,23,24,25,26]

121 In addition air polishing requires less time than traditional polishing methods [27]. Polishing

122 with a rubber cup and prophylaxis paste has been shown to remove the fluoride-rich enamel

123 and rough the enamel $[28,29]$.

124 Studies have generally found air polishing to be safe on enamel with no significant loss of

125 enamel and less abrasive than rubber-cup polishing [30]. However marked rise in aerosols with

126 air polishing, additional health hazards may potentially exist for patients, or health care

127 professionals present in the treatment room during or after a procedure [31].

128 The aim this study is to compare the effects of pre-operative air-powder polishing and rubber-

129 cup prophylaxis on tooth bleaching.

130 The null hypothesis was that there would be no difference in the change of color according to

131 the type of prophylaxis on tooth bleaching.

\section{Methods}

133 This study used randomized, controlled split-mouth experimental design to compare the effects

134 of pre-operative APD application (test side) and rubber-cup prophylaxis with paste (control

135 side) on teeth bleaching. The flow chart of study design was given in Figure 1.

136 Among the patients who applied to the Cukurova University, Dental Faculty, Department of

137 Oral Diagnosis for whitening treatment and volunteered to participate in the study and

138 redirected to Department of Restorative Dentistry.

139 The inclusion criteria were:

140 - being at least 18 years of age

141 - having minimum of 20 natural teeth (including incisors, canines, and premolars in both arches)

142 - having good oral hygiene (Plaque index $<1$, Gingival index $<1$ )

143 The exclusion criteria were: 
144 - having restorations or active caries on the anterior teeth of either arch

145 - presence of tetracycline staining or fluorosis

146 - general hypersensitivity

147 - gingival recession or periodontal disease

148 - smokers

149 - pregnant or lactating women

150 - history of prior bleaching treatment

\section{Sample size calculation}

152 The sample size analysis for paired-sample t-test was done by G-Power package program. The

153 sample size calculation was based on a previous study [32]. The expected mean difference of

154 for the color change parameter between groups was 2,2 units with a standard deviation of 3,3 -

1553,7 (the specified power of $80 \%$ and the Type I error rate of 5\%). The calculated sample size 156 was 21 patients while 23 patients $(10 \%$ more $)$ were included in the study to compensate possible

157 dropouts.

\section{Randomization}

159 The patients had bleaching treatment on the maxillary anterior area including right and left

160 canines. The registration of the patients has been done by Department of Oral Diagnosis and

161 randomly allocated by ZGBK. The right and left sides of the patients were randomized by toss

162 of a coin to receive polishing with rubber cup prophylaxis or air powder polishing system before

163 bleaching.

\section{Clinical procedures}

165 Dental prophylaxis was made by a single operator (MO). The rubber cup prophylaxis was 166 applied with low-speed handpieces. A rubber cup was attached to the prophy-angle. The

167 handpiece used at a steady slow pace of 2500-3000 rpm. The rubber cup contacted (Pro-Cup, 168 Light Blue, Soft, KerrHawe S.A., Bioggio, Switzerland) each tooth surface for an average of 5 
169 seconds together with polishing paste consisting of flour of pumice, glycerin and fluoride

170 (Cleanic, KerrHawe S.A., Bioggio, Switzerland).

171 The air polishing treatment was performed by AIRFLOW ${ }^{\circledR}$ Master device (EMS, Nyon,

172 Switzerland) with a six LED power setting (2.2 bars dynamic pressure inside powder chamber)

173 and an $11 \mathrm{LED}(35 \mathrm{~mL} / \mathrm{min}$ ) water setting for 5 seconds for each tooth (powder consumption

174 was $1.1 \mathrm{~g})$. Sodium bicarbonate air-powder polishing powder (AIR-FLOW ${ }^{\circledR}$ Plus, EMS Electro

175 Medical Systems, Nyon, Switzerland) was used. The nozzle was held 3-4 $\mathrm{mm}$ from the tooth

176 surface and the tip was angulated diagonally. The spray was delivered for an average of 5

177 seconds using a constant circular motion for each tooth. The spray was directed towards the

178 middle one-thirds of the exposed tooth [33].

179 In-office 40\% HP bleaching agent (Opalescence Xtra Boost/ Ultradent, South Jordan, UT,

180 USA) was prepared and used following the manufacturer's instructions. Opal Dam (Ultradent,

181 South Jordan, UT, USA) was used for protection of the gingiva. The bleaching gel was then

182 applied to form 1-2 mm thickness on the buccal surfaces of the teeth of both arches. The gel

183 remained on teeth for 15 minutes and was then suctioned from teeth using a surgical suction

184 tip. This application was repeated a second time in the same session.

\section{Clinical parameters}

186 Tooth color was measured using spectrophotometer VITA Easyshade V (Vita Zahnfabrik,

187 Germany). All measurements were made by a single operator under same light source between

188 1-3 pm. The spectrophotometer was calibrated before use in each participant and the device tip

189 was placed on middle thirds of the labial surface of teeth as suggested by the manufacturer's

190 manual.

191 The tooth color was measured before initial prophylaxis (baseline), after prophylaxis,

192 immediately after bleaching and after 1 week. The digital spectrophotometer used in the current

193 study measures the shade of teeth based on the CIE L*a*b* color space system [34]. This system 
194 expresses color as three values: $\mathrm{L}^{*}$ for the lightness from black $(0)$ to white $(100), \mathrm{a}^{*}$ from green

195 (-) to red $(+)$, and $b^{*}$ from blue $(-)$ to yellow $(+)$. The following values were recorded in the 196 units of CIE L*a*b* color space.

197 Color differences quantified CIELab formula $(\triangle \mathrm{Eab})$ and CIEDE2000 formula $(\Delta \mathrm{E} 00)$.

$-\Delta$ Eab calculated as: $\left[(\Delta \mathrm{L})^{2}+(\Delta \mathrm{a})^{2}+(\Delta \mathrm{b}) 2\right]^{1 / 2}$

$-\Delta \mathrm{E} 00$ calculated as: $\left[(\Delta \mathrm{L} / \mathrm{k} \mathrm{L} \mathrm{S} \mathrm{L})^{2}+(\Delta \mathrm{C} / \mathrm{k} \mathrm{C} \mathrm{S} \mathrm{C})^{2}+(\Delta \mathrm{H}\right.$

Where $\Delta \mathrm{E} 00$ is the change in color; $\mathrm{RT}$ is a hue rotation term; $\Delta \mathrm{L}, \Delta \mathrm{C}$, and $\Delta \mathrm{H}$ are the compensation differences for neutral colors (primed values; L,C,H); SL is the compensation for lightness; $\mathrm{SC}$ is the compensation for chroma; $\mathrm{SH}$ is the compensation for hue; and $\mathrm{kL}, \mathrm{kC}$, and

$204 \mathrm{kH}$ are constants and usually unity.

$205 \Delta$ SGU: The other bleaching scale shade guide (SGU) unit also used to monitör tooth whitting

206 prpcess. While making SGU measurements, the bleached index is set according to the VITA 207 Bleached guide 3D-MASTER at spectrophotometer for the measured shade. The measured 208 bleached index after treatment was subtracted from the baseline value.

\section{Statistical Analysis}

210 The assumption of normal distribution of difference scores were examined prior to conducting

211 the analysis. The assumption was considered satisfied for many differences of color scores,

212 some of them not satisfied which were indicated with asterisk $(*)$ in Table 1.

213 The proper reporting for non-normal distributed (skewed) data were summarized by 214 using median (minimum and maximum) value instead of mean and standard deviation. Because 215 of a consistent illustration in the Table 1 for parametric and non-parametric tests the both 216 descriptive statistics mean $\pm \mathrm{SD}$, and Median (min, max) noted across all treatment levels. 
217 The differences of color scores of the teeth were assessed for normality assumption by Shapiro-

218 Wilks test $(\mathrm{p}>0.05)$ and homogeneity of variances were assessed by Levene's Test for Equality

219 of variances $(\mathrm{p}>0.05)$.

220 The paired t-test were used if the normality assumptions were valid, otherwise the Wilcoxon-

221 signed rank test were used to compare the rubber-cup and air-powder polishing treatments, and

222 for the differences of 1 week and immediate values.

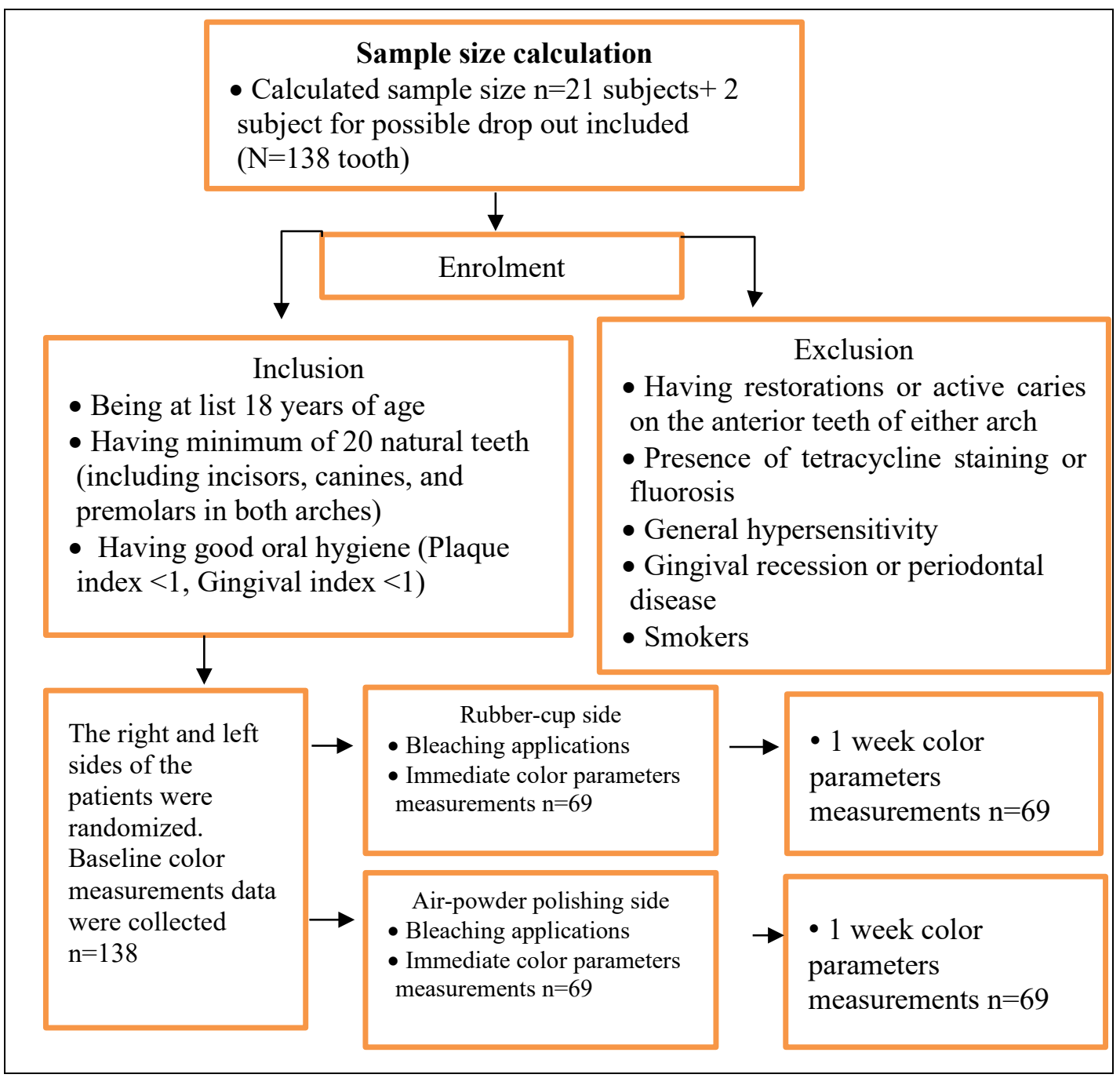

Figure 1. The flow chart of study design. 


\section{Results}

229 All included patients completed the study protocol without any adverse events. 14 female and 2309 male participated in the study. The mean age of patients was $34.1 \pm 8.9$.. The baseline 231 measurements are shown in Table 1.

232 After dental prophylaxis, in the RCP group were $3.177 \pm 1.756$ and $1.878 \pm 0.957$, respectively. 233 In APP group, $\Delta \mathrm{Eab}$ and $\Delta \mathrm{E} 00$ were $2.699 \pm 1.462$ and $1.569 \pm 0.765$, respectively. There was 234 no significant difference at the baseline CIE L*, a*, $b^{*}$ value between the groups $(p>0,05)$ 235 (Table 2).

236 At immediate assessment period the color parameters $(\Delta \mathrm{L}, \Delta \mathrm{a}, \Delta \mathrm{b}, \Delta \mathrm{SGU}, \Delta \mathrm{Eab}, \Delta \mathrm{E} 00)$ were 237 significantly different assessment period $(\mathrm{p}<0,05)$. The mean $\Delta \mathrm{Eab}$ and $\Delta \mathrm{E} 00$ and $\Delta \mathrm{SGU}$ were

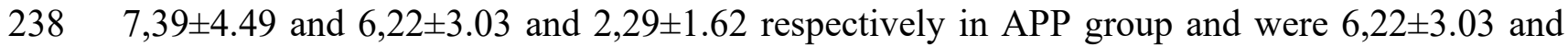
239

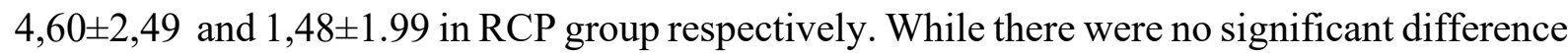
240 between air-powder polishing and rubber-cup groups (Table 3).

241 At 1 week assessment period the color parameters $(\Delta \mathrm{L}, \Delta \mathrm{a}, \Delta \mathrm{b}, \Delta \mathrm{SGU}, \Delta \mathrm{Eab}, \Delta \mathrm{E} 00)$ were 242 significantly different assessment period $(\mathrm{p}<0,05)$. In APP group the mean $\Delta \mathrm{Eab}$ and $\Delta \mathrm{E} 00$ and $\Delta$ SGU were 10,94 \pm 4.91 and 7,65 $\pm 3,91$ and 5,09 \pm 2.23 respectively, and in RCP group the mean

$244 \Delta \mathrm{Eab}$ and $\Delta \mathrm{E} 00$ and $\triangle \mathrm{SGU}$ were $9,08 \pm 2.84$ and $5,6 \pm 2,65$ and $4,62 \pm 2.67$ respectively. There 245 was no statistically significant differences between the ARP and RCP groups for $\triangle \mathrm{Eab}$ and $246 \Delta$ SGU means, while $\Delta \mathrm{E} 00$ mean difference was statistically different at 1 week period (Table $2474)$.

248 When the prophylaxis groups were compared with each other for all color parameters, there 249 was no significant difference during immediate and 1-week assessment periods.

250 The mean change of $\Delta \mathrm{Eab}, \Delta \mathrm{SGU}, \Delta \mathrm{E} 00$ were significant from immediate to 1-week 251 assessment periods in air-powder polishing group and in rubber-cup group $(\mathrm{p}<0,05)$. 
252 The mean change of $\Delta \mathrm{E} 00(2,22 \pm 2,11)$ was significant from immediate to 1 -week assessment

253 periods in APP group, $(\mathrm{p}<0.001)$ and also in rubber-cup group the mean change of $\Delta \mathrm{E} 00$

$254(1,0 \pm 1,2)$ was statistically significant $(\mathrm{p}=0.012)$.

255 The mean change of $\Delta \mathrm{SGU}(3.14 \pm 2.83)$ value was significant from immediate to 1-week

256 treatment period in rubber-cup group, $\mathrm{p}<0.001$, and also in the air-powder polishing group the 257 mean change of SGU (2.80 \pm 1.89$)$ was statistically significant, $\mathrm{p}<0.001$.

\section{Discussion}

259 This study evaluated the influence of dental prophylaxis technique prior tooth bleaching in the 260 change of color. Our results suggest that the dental prophylaxis technique before bleaching 261 treatment affects the bleaching color results, thus rejecting the null hypothesis.

262 CIELab and CIEDE2000 have been developed to identify the color differences of objects. 263 Studies have revealed that the $\Delta$ E2000 reflects small color differences better with the way 264 human observers perceive [35,36].

$265 \Delta$ Eab acceptability threshold (AT) in the literature ranges from 2.0 to 4.0 , as much as half of 266 the literature refers to its value as being 3,3 or 3,7 [37]. After dental prophylaxis, in the APP 267 group $\Delta \mathrm{Eab}$ and $\Delta \mathrm{E} 00$ were $3.177 \pm 1.756$ and $1.878 \pm 0.957$, respectively. In RCP group, $\Delta \mathrm{Eab}$ and $\Delta \mathrm{E} 00$ were $2.699 \pm 1.462$ and $1.569 \pm 0.765$, respectively. Values in both groups were

269 below $\Delta$ Eab acceptability threshold. The $\Delta \mathrm{E} 00$ acceptability threshold value was considered to 270 be 1.8 [38]. With reference to $\triangle \mathrm{E} 00$, the APP group was above the acceptability threshold value.

271 There was no statistical difference between techniques in the color change of teeth after 272 prophylaxis $(\mathrm{p}>0,05)$. Pereira et al. reported that tooth color change below the threshold values 273 after prophylaxis with a nylon brush with prophylaxis paste [39]. This finding is similar to our 274 results.

275 To our knowledge, there are no studies comparing the effects of prior APP and rubber cup 276 prophylaxis on the bleaching effectiveness which makes the interpretation of the results 
impossible. Results of previous study comparing the effectiveness of air-polishing to the rubber cup polishing for bacterial plaque and stain removal demonstrate that both methods are equally effective with similar gingival trauma [40]. While a study report APDs to be more effective for plaque and stain removal in pits and fissures [41] and complete cleaning, down to the tooth microstructure [42] ; another indicates that polishing with rubber cup was more effective for the crown and root surface smoothening and debris removal [23]. The main disadvantage of rubber-cup prohylaxis is that the polishing pastes abrade, flatten, and deposit debris into the microcavities voids on the enamel surface [42] which may theoretically decrease bleaching effectiveness. This may be the reason why the APP is more effective than RCP on bleaching in our study. In addition, Nakamura et al. [44] reported that tooth polishing with a polishing agent and a brush caused a decrease in lightness and reduction of yellowness. The polishing with rubber cup and prophylaxis paste is highly operator-sensitive as rotation speed, abrasiveness of paste, pressure applied with hand piece and duration influence affect the efficacy of the procedure [45]. On the other hand, the aerosols generated by air polishing may present an infection control hazard hence, preprocedural rinse is always recommended along with aerosol reduction devices [46].

Previous literatures have shown that whitening from bleaching agents is manifested mainly by an increase in lightness (higher L) and reduction in yellowness (lower b) and redness (lower a) $[47,48]$. There were increase in the $\mathrm{L}$ value and decrease in a and $\mathrm{b}$ values immediately after the bleaching treatment in both groups.

After 1 week, statistically significant developments obtained according to baseline measurements in all these three values. There are significant differences in $\Delta \mathrm{a}$ and $\Delta \mathrm{b}$ values in the rubber-cup group and $\Delta \mathrm{L}$ in air-flow group from immediate to 1-week measurements. Some studies found that the variance in $\mathrm{b}$ and $\mathrm{L}$ values had major influence on color change 
$301[49,50]$. In the judgement of whiteness of tooth none of $a, b$ or L value distinctly evaluated, 302 hence all off them equally valuable for the calculation of $\Delta \mathrm{E}$ value.

303 At 1 week period there was no difference between the groups between $\Delta$ Eab and $\Delta$ SGU while $304 \Delta \mathrm{E} 00$ was statistically significant differences. This is due to the difference in the $\Delta \mathrm{E} 00$ 305 calculation technique. There are few studies on color changes after bleaching using this 306 CIEDE2000 formula [51]. This may be because the regression lines of $\Delta$ Eab on $\Delta E 00$ change 307 from linear to curvilinear shapes when the values increases in color space. Hence in significant 308 test we can reach different conclusion for $\Delta \mathrm{Eab}$ and $\Delta \mathrm{E} 00$ [52].

309 It was reported that the bleaching activity peaked on the 7th day, therefore in our study the 310 observations were measureed at one week after treatments [53]. ADP might benefit bleach 311 results and patient and might be considered as the best choice for dental prophylaxis before 312 bleaching treatment.

313 The split-mouth design used in this study allows different experimental groups within the same 314 patient [54]. Thus, each patient served as his or her own control. This eliminates patient 315 dependent variables on the results. In order to be more precise and objective, the 316 spectrophotometer measurement was preferred over the visual evaluation [55]. Besides this, a 317 positioning guide with orifices in the center of the middle third of teeth was fabricated [56].

318 This was because the middle area of teeth is generally flatter and provides a stable platform for 319 the spectrophotometer sensor [57], and this area is the most representative tooth-color region 320 as it reflects the light from the dentin with little influence from the enamel [56-58].

321 The limitations of this study are structural differences between teeth. The amount of bleaching 322 agent that penetrates the tooth structure is affected by the thickness of enamel and dentin [59]. 323 The CIEDE 20000 formulation is the most modern method and better reflects visual differences 324 between colors. The use of the CIEDE 2000 formulation is recommended for future bleaching 325 color evaluation studies. 


\section{Conclusions}

327 The results of the study show that both rubber cup prophylaxis and APP devices can be used in 328 fact APP may be considered as the best choice for dental prophylaxis technique before 329 bleaching treatment.

\section{Abbreviations}

331 APD: Air-Powder polishing Devices, RCP: rubber-cup polishing, CIE: Commission 332 Internationale de 1'Eclairage (International Commission on Illumination), L*: Lightness, a*: 333 Red/Green Value, b*: Blue/Yellow Value, E*: Degree of color variation, SGU: Shade Guide 334 Units, HP: Hydrogen Peroxide, SD: Standard Deviation, LED: Light Emitting Diode, rpm: 335 Revelution per minute, mm: millimeter

\section{Declarations}

\section{Ethics approval and consent to participate}

338 Informed consent forms were signed by all participants.

339 The protocol was reviewed and approved by Ethics Committee of Cukurova University (No: 1$340 \quad 6-18-78 / 78)$.

\section{Consent for publication}

342 Not applicable.

\section{Availability of data and materials}

344 Not applicable.

\section{Competing interests}

346 The authors declare that they have no competing interests.

\section{Funding}

348 The protocol was supported by Research Fund of Cukurova University (Project Number: TSA-

349 2018-10847). This funding source had no role in the design of this study, the collection, 350 analysis, and interpretation of data and writing the manuscript. 


\section{Authors' contributions}

352 ZGBK developed the study outlines and coordinated the protocol. Voluntary patients registered 353 by $\mathrm{MO}$ and random allocations have been done by ZGBK. All prophylaxis procedures were 354 performed by MO. All bleaching procedures were performed by ZGBK. ZGBK was involved 355 in measuring data and writing the first draft of the manuscript, and MO contributed to revision 356 of the final draft. All authors read and approved the final manuscript.

\section{Acknowledgements}

358 The authors would like to acknowledge Prof. Dr. Yuksel Bek, Ondokuz Mayıs University, 359 Department of Biostatistics and Medical Informatics, Turkey, for him assistance in statistical 360 analysis.

\section{REFERENCES}

362 1. Féliz-Matos L, Hernández LM, Abreu N. Dental Bleaching Techniques; Hydrogencarbamide Peroxides and Light Sources for Activation, an Update. Mini Review Article..Open Dent J. 2014;8:264-8.

2. Gallagher A, Maggio B, Bowman J, Borden L, Mason S, Felix H. Clinical study to compare two in-office (chairside) whitening systems. J Clin Dent. 2002;13:219-24.

3. Joiner A. The bleaching of teeth: a review of the literature. J Dent. 2006;34:412-9.

4. Seghi R, Denry I. Effects of external bleaching on indentation and abrasion characteristics of human enamel in vitro. J Dent Res. 1992;71:1340-4.

5. Abdullah A, Muhammed F, Zheng B, Liu Y: An overview of extrinsic tooth bleaching and its impact on oral restorative materials. World Journal of Dentistry 2017;8(6):503-10. 6. FC Marson, RS Gonçalves, CO Silva, LTÂ Cintra, RC Pascotto, PH dos Santos, ALF Briso. Penetration of Hydrogen Peroxide and Degradation Rate of Different Bleaching Products. Oper Dent. 2015;40:72-9. 
7. Goldberg M, Grootveld M, Lynch E. Undesirable and adverse effects of toothwhitening products: a review. Clin Oral Investig. 2010;14:1-10.

8. Ogura K, Tanaka R, Shibata Y, Miyazaki T, Hisamitsu H. In vitro demineralization of tooth enamel subjected to two whitening regimens. J Am Dent Assoc. 2013;144:799807.

9. Grazioli G, Valente LL, Isolan CP, Pinheiro HA, Duarte CG, Münchow EA. Bleaching and enamel surface interactions resulting from the use of highly-concentrated bleaching gels. Arch Oral Biol. 2018;87:157-62.

10. Soares DG, Basso FG, Hebling J, de Souza Costa CA. Concentrations of and application protocols for hydrogen peroxide bleaching gels: effects on pulp cell viability and whitening efficacy. J Dent. 2014;42:185-98.

11. Vaz MM, Lopes LG, Cardoso PC, Souza JBd, Batista AC, Costa NL, Torres ÉM, Estrela C. Inflammatory response of human dental pulp to at-home and in-office tooth bleaching. J Appl Oral Sci. 2016;24:509-17.

12. Cintra LTA, Benetti F, da Silva Facundo AC, Ferreira LL, Gomes-Filho JE, Ervolino E, Rahal V, Briso ALF. The number of bleaching sessions influences pulp tissue damage in rat teeth. J Endod. 2013;39:1576-80.

13. Soares DG, Ribeiro APD, da Silveira Vargas F, Hebling J, de Souza Costa CA. Efficacy and cytotoxicity of a bleaching gel after short application times on dental enamel. Clin Oral Investig. 2013;17:1901-9.

14. Coldebella CR, Ribeiro APD, Sacono NT, Trindade FZ, Hebling J, Costa CAdS. Indirect cytotoxicity of a $35 \%$ hydrogen peroxide bleaching gel on cultured odontoblast-like cells. Braz Dent J. 2009;20:267-74.

15. Lima AF, Lessa FCR, Mancini MNG, Hebling J, de Souza Costa CA, Marchi GM. 
released from bleaching agents. Oral Surg Oral Med Oral Pathol Oral Radiol Endod. 2010;109:70-6.

16. Soares D, Ribeiro A, Sacono N, Coldebella C, Hebling J, de Souza Costa C. Transenamel and transdentinal cytotoxicity of carbamide peroxide bleaching gels on odontoblast-like MDPC-23 cells. Int Endod J. 2011;44116-25.

17. Trindade F, Ribeiro A, Sacono N, Oliveira C, Lessa F, Hebling J, Costa CAdS. Transenamel and trans-dentinal cytotoxic effects of a $35 \% \mathrm{H}_{2} \mathrm{O}_{2}$ bleaching gel on cultured odontoblast cell lines after consecutive applications. Int Endod J. 2009;42:516-24.

18. Lee D, Lim B-S, Lee Y-K, Yang H-C. Effects of hydrogen peroxide $\left(\mathrm{H}_{2} \mathrm{O}_{2}\right)$ on alkaline phosphatase activity and matrix mineralization of odontoblast and osteoblast cell lines. Cell Biol Toxicol. 2006;22:39-46.

19. Matsui S, Takahashi C, Tsujimoto Y, Matsushima K. Stimulatory effects of lowconcentration reactive oxygen species on calcification ability of human dental pulp cells. J Endod. 2009;35:67-72.

20. BA Matis, U Gaiao, D Blackman, FA Schultz, GJ Eckert. In vivo degradation of bleaching gel used in whitening teeth. J Am Dent Assoc. 1999;130:227-35. Literature. J Dent Hyg. 2013;87:173-80.

22. Kihn PW. Vital tooth whitening. Dent Clin North Am. 2007;51:319-31.

23. deWet FA, Holtzhausen T, Nel JJ. Evaluation of a new prophylaxis device. J Dent Assoc S Afr. 1984;39:207-8. 1984;156:287-91. 
Prophy-Jet as an instrument for routine removal of tooth stain and plaque. J Periodontol. $1984 ; 55: 486-8$.

26. Berkstein S, Reiff RL, McKinney JF, Killoy WJ: Supragingival root surface removal during maintenance procedures utilizing an air-powder abrasive J Periodontol. 1987;58:327-30.

27. Patil SS, Rakhewar PS, Limaye PS, Chaudhari NP. A comparative evaluation of plaque-removing efficacy of air polishing and rubber-cup, bristle brush with paste polishing on oral hygiene status: A clinical study. J Int Soc Prev Community Dent. $2015 ; 5: 457-62$.

28.Vrbic V, Brudevold F, McCann HG. Acquisition of fluoride by enamel from fluoride pumice pastes. Helv Odont Acta. 1967;11:21-6.

29. Koch G, Petersson LG, Johnson G. Abrasive effect and fluorine uptake from polishing and prophylactic pastes. Swed Dent J. 1975;68:1-7.

30. Gutmann ME. Air polishing: a comprehensive review of the literature. Journal of dental Hyg. 1998;72:47-56.

31. Legnani P, Checchi L, Pelliccioni G, D'Achille C. Atmospheric contamination during dental procedures. Quintessence Int. 1994;25:435-9.

32. Bernardon JK, Ferrari P, Baratieri LN, Rauber GB. Comparison of treatment time versus patient satisfaction in at-home and in-office tooth bleaching therapy. J Prosthet Dent. 2015;114:826-30.

33. Sawai MA, Bhardwaj A, Jafri Z, Sultan N, Daing A. Tooth polishing: The current status. J Indian Soc Periodontol. 2015;19:375-80. 
35. Comparison of the CIELab and CIEDE2000 color difference formulas Gómez-Polo C, Portillo Muñoz M, Lorenzo Luengo MC, Vicente P, Galindo P, Martín Casado AM. J Prosthet Dent. 2016;115:65-70.

36. del Mar Pérez M, Saleh A, Yebra A, Pulgar R. Study of the variation between CIELAB delta $E^{*}$ and CIEDE2000 color-differences of resin composites. Dent Mater J. 2007;26:218.

37. Khashayar G, Bain PA, Salari S, Dozic A, Kleverlaan CJ, Feilzer AJ. Perceptibility and acceptability thresholds for colour differences in dentistry. J Dent. 2014;42:637-44. Takahashi H, Tashkandi E, Perez Mdel M. Color difference thresholds in dentistry. J Esthet Restor Dent. 2015;27:S1-S9.

39. Pereira R, Corado D, Silveira J, Alves R, Mata A, Marques D. Dental prophylaxis influence in tooth color assessment—Clinical study J Esthet Restor Dent. 2020;32:586-92. by Prophy-Jet and rubber-cup polishing techniques using aluminium trihydroxide Indian J Dent. 2015;6:130-4.

42. Camboni S, Donnet M. Tooth surface comparison after air polishing and rubber cup: a

41. Garcia-Godoy F, Medlock J. An SEM study of the effects of air-polishing on fissure scanning electron microscopy study. J Clin Dent. 2016;27:13-8. surfaces. Quintessence Int. 1988;19:465-7.

43. Chowdhary Z, Mohan R. Efficiency of three different polishing methods on enamel and cementum: A scanning electron microscope study. J Indian Soc Periodontol. $2018 ; 22: 18-24$

44. Nakamura T, Saito O, Ko T, Maruyama T. The effects of polishing and bleaching on the colour of discoloured teeth in vivo. Journal of oral rehabilitation. 2001;28:1080-22. 
45. Petersilka GJ, Ehmke B, Flemmig TF. Antimicrobial effects of mechanical debridement. Periodontol 2000. 2002;28:56-71.

46. Muzzin KB, King TB, Berry CW. Assessing the clinical effectiveness of an aerosol reduction device for the air polisher. J Am Dent Assoc. 1999;1301354-9.

47. Wiegand A, Drebenstedt S, Roos M, Magalhães AC, Attin T. 12-Month color stability of enamel, dentine, and enamel-dentine samples after bleaching. Clin oral investig. 2008;12:303-10.

48. Giachetti L, Bertini F, Bambi C, Nieri M, Russo DS. A randomized clinical trial comparing at-home and in-office tooth whitening techniques: a nine-month follow-up. J Am Dent Assoc. 2010;141:1357-64.

49. Lenhard M. Assessing tooth color change after repeated bleaching: in vitro with a 10 percent carbamide peroxide gel. J Am Dent Assoc. 1996;127:1618-24.

50. Barry TN, Bailey C, Ashcraft-Olmscheid D, Vandewalle KS. Effect of a new bleaching gel on tooth whitening. Oper Dent. 2017;42:559-66.

51. Surmelioglu D, Usumez A. Effectiveness of Different Laser-Assisted InOffice Bleaching Techniques: 1-Year Follow-Up. Photobiomodul Photomed Laser Surg. 2020;38:632-9.

52. Koçak EF, Ekren O, Johnston WM, Uçar Y.Analysis of color differences in stained contemporary esthetic dental materials. J Prosthet Dent. 2020;18;S00223913(20)30433-9.

53. BA Matis, MA Cochran, G Wang, GJ Eckert. A Clinical Evaluation of Two In-office Bleaching Regimens With and Without Tray Bleaching. Oper Dent. 2009 ;34:142-9.

54. Da Costa J, Lubisich E, Ferracane J, Hilton T. Comparison of efficacy of an in-office whitening system used with and without a whitening priming agent. J Esthet Restor Dent. 2011;23:97-104. 
55. Chu SJ, Trushkowsky RD, Paravina RD. Dental color matching instruments and systems. Review of clinical and research aspects. J Dent. 2010;38 Suppl 2:2-16.

56. Darriba IL, Melón PC, Sartal AG, Sousa IR, de la Peña VA. Influence of treatment duration on the efficacy of at-home bleaching with daytime application: a randomized clinical trial. Clin Oral Investig. 2019;23:3229-37.

57. Yuan JC-C, Brewer JD, Monaco Jr EA, Davis EL. Defining a natural tooth color space based on a 3-dimensional shade system. J Prosthet Dent. 2007;98:110-9.

58. Schwabacher WB, Goodkind RJ, Lua MJ: Interdependence of the hue, value, and chroma in the middle site of anterior human teeth. J Prosthodont. 1994;3:188-92. (2007) Penetration of $38 \%$ hydrogen peroxide into the pulp chamber in bovine and 1074-7. 


\begin{tabular}{|c|c|c|}
\hline & \multicolumn{2}{|l|}{ baseline } \\
\hline & Mean \pm sd & $\begin{array}{l}\text { Median } \\
\text { (min;max) }\end{array}$ \\
\hline $\mathrm{L}$ & & \\
\hline APP & $\begin{array}{l}70.84 \\
\pm 6.00\end{array}$ & $\begin{array}{l}71.20 \\
(60.2 ; 82.4)\end{array}$ \\
\hline $\mathrm{RCP}$ & $\begin{array}{l}71.70 \\
\pm 4.14\end{array}$ & $\begin{array}{l}71.40 \\
(61.9 ; 78.1)\end{array}$ \\
\hline $\mathrm{p}$ & 0.592 & \\
\hline $\mathrm{a}$ & & \\
\hline APP & $\begin{array}{l}1.29 \\
\pm 1.65\end{array}$ & $\begin{array}{l}1.20 \\
(-1.9 ; 3.5)\end{array}$ \\
\hline $\mathrm{RCP}$ & $\begin{array}{l}1.28 \\
\pm 1.17\end{array}$ & $\begin{array}{l}1.10 \\
(-0.6 ; 3.4)\end{array}$ \\
\hline $\mathrm{p}$ & 0.981 & \\
\hline $\mathrm{b}$ & & \\
\hline$\overline{\text { APP }}$ & $\begin{array}{l}24.23 \\
\pm 6.31\end{array}$ & $\begin{array}{l}22.60 \\
(15.3 ; 34.8)\end{array}$ \\
\hline$\overline{\mathrm{RCP}}$ & $\begin{array}{l}24.73 \\
\pm 5.71\end{array}$ & $\begin{array}{l}24.7 \\
(17.3 ; 37.1)\end{array}$ \\
\hline $\mathrm{p}$ & 0.604 & \\
\hline
\end{tabular}


530

\begin{tabular}{|c|c|c|}
\hline $\begin{array}{l}\text { Color } \\
\text { parameters }\end{array}$ & Mean \pm sd & $\mathrm{p}$ \\
\hline \multicolumn{3}{|l|}{$\Delta \mathbf{L}$} \\
\hline $\mathrm{RCP}$ & $1,850 \pm 1,359$ & \multirow[t]{2}{*}{0,500} \\
\hline APP & $2,239 \pm 1,676$ & \\
\hline \multicolumn{3}{|l|}{$\Delta \mathbf{a}$} \\
\hline $\mathrm{RCP}$ & $-0,433 \pm 0,281$ & \multirow[t]{2}{*}{0,288} \\
\hline APP & $-0,550 \pm 0,357$ & \\
\hline \multicolumn{2}{|l|}{$\Delta \mathbf{b}$} & \\
\hline RCP & $-1,378 \pm 1,447$ & \multirow[t]{2}{*}{0,632} \\
\hline APP & $-1,611 \pm 1,566$ & \\
\hline \multicolumn{2}{|l|}{$\Delta$ Eab } & \\
\hline $\mathrm{RCP}$ & $2,699 \pm 1,462$ & \multirow[t]{2}{*}{0,381} \\
\hline APP & $3,177 \pm 1,756$ & \\
\hline \multicolumn{2}{|l|}{$\Delta \mathrm{E} 00$} & \\
\hline $\mathrm{RCP}$ & $1,569 \pm 0,765$ & \multirow[t]{2}{*}{0,295} \\
\hline APP & $1,878 \pm 0,957$ & \\
\hline \multicolumn{2}{|l|}{$\Delta \mathbf{S G U}$} & \\
\hline $\mathrm{RCP}$ & $0,7 \pm 0,58$ & \multirow[b]{2}{*}{0,571} \\
\hline APP & $1 \pm 0,86$ & \\
\hline
\end{tabular}

531

532

533

534

535

536 
537 Table 3: Mean \pm standart deviations and change from baseline to immediate for $\Delta \mathrm{L}, \Delta \mathrm{a}, \Delta \mathrm{b}$,

$538 \Delta \mathrm{Eab}, \Delta \mathrm{E} 00$ and $\Delta \mathrm{SGU}$

\begin{tabular}{|c|c|c|}
\hline Color Parameters & Mean \pm sd & Baseline -Immediate p value \\
\hline \multicolumn{3}{|l|}{$\Delta \mathbf{L}$} \\
\hline APP & $5,41 \pm 5.40$ & 0,001 \\
\hline RCP & $4,9 \pm 4.39$ & 0,001 \\
\hline $\mathbf{p}$ & 0,667 & \\
\hline \multicolumn{3}{|l|}{$\Delta \mathrm{a}$} \\
\hline APP & $-0,69 \pm 1.41$ & 0,003 \\
\hline RCP & $-0,15 \pm 1.26$ & 0,003 \\
\hline $\mathbf{p}$ & 0,111 & \\
\hline \multicolumn{3}{|l|}{$\Delta \mathbf{b}$} \\
\hline APP & $-1,56 \pm 3.96$ & 0,001 \\
\hline $\mathrm{RCP}$ & $-0,55 \pm 2.78$ & 0,001 \\
\hline $\mathbf{p}$ & 0,281 & \\
\hline \multicolumn{3}{|l|}{$\Delta$ Eab } \\
\hline APP & $7,39 \pm 4.49$ & \\
\hline $\mathrm{RCP}$ & $6,22 \pm 3.03$ & \\
\hline $\mathbf{p}$ & 0,129 & \\
\hline \multicolumn{3}{|l|}{$\Delta \mathrm{E} 00$} \\
\hline APP & $5,43 \pm 3,44$ & \\
\hline $\mathrm{RCP}$ & $4,60 \pm 2,49$ & \\
\hline $\mathbf{p}$ & 0,195 & \\
\hline \multicolumn{3}{|l|}{$\Delta$ SGU } \\
\hline APP & $2,29 \pm 1.62$ & \\
\hline $\mathrm{RCP}$ & $1,48 \pm 1.99$ & \\
\hline $\mathbf{p}$ & 0,148 & \\
\hline
\end{tabular}

539 values in last colon belong to period differences, $\mathrm{p}$ values in rows belong to group differences 
Table 4: Mean \pm standart deviations and change from baseline to 1 week for $\Delta \mathrm{L}, \Delta \mathrm{a}, \Delta \mathrm{b}$, $\Delta \mathrm{Eab}, \Delta \mathrm{E} 00$ and $\Delta \mathrm{SGU}$

\begin{tabular}{|c|c|c|}
\hline Color Parameters & Mean \pm sd & Baseline - 1 week p value \\
\hline \multicolumn{3}{|l|}{$\Delta \mathbf{L}$} \\
\hline APP & $8,54 \pm 5.99$ & 0,001 \\
\hline $\mathrm{RCP}$ & $5,95 \pm 4.80$ & 0,001 \\
\hline $\mathbf{p}$ & 0,153 & \\
\hline \multicolumn{3}{|l|}{$\Delta \mathbf{a}$} \\
\hline APP & $-0,78 \pm 2.12$ & 0,003 \\
\hline RCP & $-1,45 \pm 0.87$ & 0,001 \\
\hline $\mathbf{p}$ & $0.211^{*}$ & \\
\hline \multicolumn{3}{|l|}{$\overline{\Delta \mathbf{b}}$} \\
\hline APP & $-2,38 \pm 5.40$ & 0,001 \\
\hline RCP & $-3,36 \pm 3.09$ & 0,001 \\
\hline $\mathbf{p}$ & 0,437 & \\
\hline \multicolumn{3}{|l|}{$\overline{\Delta \text { Eab }}$} \\
\hline APP & $10,94 \pm 4.91$ & \\
\hline $\mathrm{RCP}$ & $9,08 \pm 2.84$ & \\
\hline $\mathbf{p}$ & 0,091 & \\
\hline \multicolumn{3}{|l|}{$\overline{\Delta \mathrm{E} 00}$} \\
\hline APP & $7,65 \pm 3,91$ & \\
\hline $\mathrm{RCP}$ & $5,6 \pm 2,65$ & \\
\hline $\bar{p}$ & 0,036 & \\
\hline \multicolumn{3}{|l|}{$\overline{\Delta \mathrm{SGU}}$} \\
\hline APP & $5,09 \pm 2.23$ & \\
\hline RCP & $4,62 \pm 2.67$ & \\
\hline p & 0,484 & \\
\hline
\end{tabular}

547 APP: air-powder polishing, RCP: rubber-cup polishing

$548 \quad(*)$ Asterisk indicates the $\mathrm{p}$ values belong to Wilcoxon signed rank test statistics, the other $\mathrm{p}$ values belong to 549 paired t-test statistics. 


\begin{tabular}{|c|c|c|}
\hline Color Parameters & Mean \pm sd & Immediate-1 week p value \\
\hline \multicolumn{3}{|l|}{$\Delta \mathbf{L}$} \\
\hline APP & $3,13 \pm 3.60$ & 0,001 \\
\hline RCP & $1,05 \pm 5.08$ & 0,354 \\
\hline $\mathbf{p}$ & 0,063 & \\
\hline \multicolumn{3}{|l|}{$\Delta \mathbf{a}$} \\
\hline APP & $-0,09 \pm 2.77$ & $0.181 *$ \\
\hline RCP & $-1,3 \pm 1.62$ & $0.002 *$ \\
\hline $\mathbf{p}$ & 0,081 & \\
\hline \multicolumn{3}{|l|}{$\Delta \mathbf{b}$} \\
\hline APP & $-0,82 \pm 5.26$ & 0,484 \\
\hline RCP & $-2,8 \pm 3.70$ & 0,002 \\
\hline $\mathbf{p}$ & 0,119 & \\
\hline \multicolumn{3}{|l|}{$\Delta$ Eab } \\
\hline APP & $3,55 \pm 3.55$ & $<0.001$ \\
\hline RCP & $2,86 \pm 2.80$ & $<0.001$ \\
\hline $\mathbf{p}$ & 0,359 & \\
\hline \multicolumn{3}{|l|}{ E00 } \\
\hline APP & $2,22 \pm 2,11$ & $<0.001$ \\
\hline $\mathrm{RCP}$ & $1 \pm 1,2$ & 0.012 \\
\hline $\mathbf{p}$ & 0,364 & \\
\hline \multicolumn{3}{|l|}{$\Delta \mathbf{S G U}$} \\
\hline APP & $2,8 \pm 1.89$ & $<0.001 *$ \\
\hline $\mathrm{RCP}$ & $3,14 \pm 2.83$ & $<0.001$ \\
\hline $\mathbf{p}$ & 0,591 & \\
\hline
\end{tabular}

555 APP: air-powder polishing, RCP: rubber-cup polishing

556 (*) Asterisk indicates the $\mathrm{p}$ values belong to Wilcoxon signed rank test statistics, the other $\mathrm{p}$ values belong to 557 paired t-test statistics. 


\section{Figures}

\section{Sample size calculation}

- Calculated sample size $n=21$ subjects +2 subject for possible drop out included $(\mathrm{N}=138$ tooth)

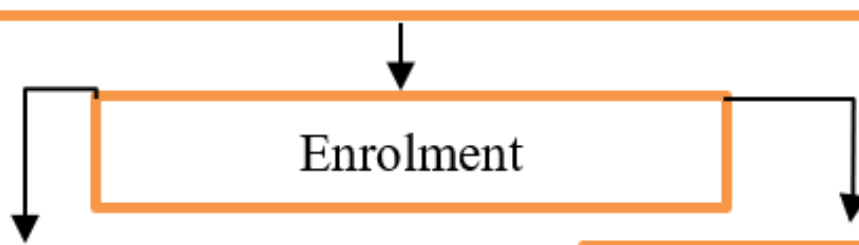

\section{Inclusion}

- Being at list 18 years of age

- Having minimum of 20 natural teeth (including incisors, canines, and premolars in both arches)

- Having good oral hygiene (Plaque index $<1$, Gingival index $<1$ )

\section{Exclusion}

- Having restorations or active caries on the anterior teeth of either arch

- Presence of tetracycline staining or fluorosis

- General hypersensitivity

- Gingival recession or periodontal disease

- Smokers

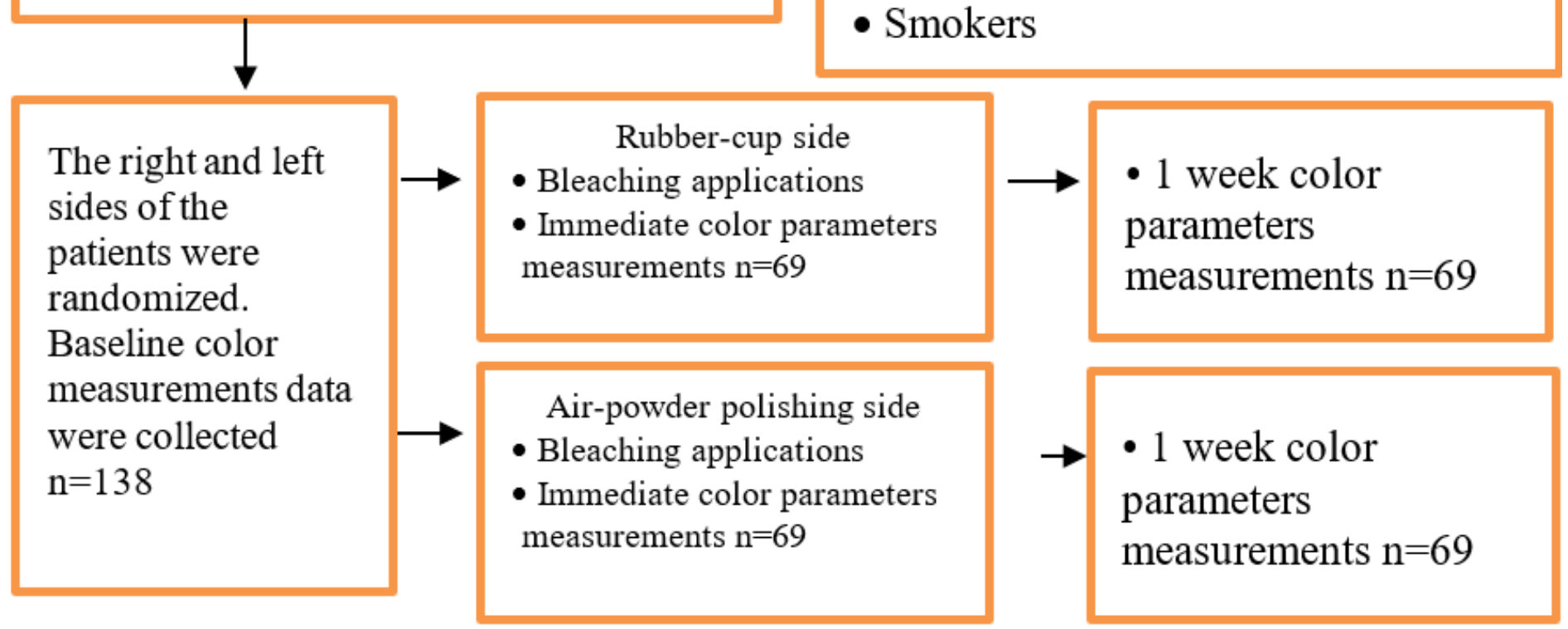

Figure 1

The flow chart of study design.

\section{Supplementary Files}

This is a list of supplementary files associated with this preprint. Click to download. 
- CONSORT2010checklistofinformationtoincludewhenreportingarandomisedtrial.docx 